\title{
RISK ANALYSIS FOR ENVIRONMENTAL HAZARDS: THE CASE OF OIL SPILLS, IN CRETE
}

\section{P. A. KASSOMENOS}

Received: 18/02/03

Accepted: 11/11/03
University of loannina,

Department of Physics,

Laboratory of Meteorology,

GR-45110, Ioannina, Greece

Tel: + (30) 26510-98470, Fax: + (30) 26510-98699

e-mail: pkassom@cc.uoi.gr

\section{ABSTRACT}

In this paper a review of most recent practices in the field of Risk analysis are presented. Then the available data for oil spill incidents in the area of Crete covering the period 1995-1999 are analysed and discussed in detail. Risk analysis tables are produced in order to formulate the spatial, temporal (yearly and monthly) risk of an incident, the correlation with the prevailing wind fields in both northern and southern Crete, and the possibility of an early intervention the relevant authorities located at the major port of Heraklion. Then the possible risk of an oil spill incident is discussed in relation to various sensitive social or financial activities as well as to environmentally protected areas. Finally a formula is proposed and applied in order to combine the various risks from an oil spill incident. As it was found, northern Crete and especially the marine areas of Heraklion and Chania are most prompt for an oil spill accident and its consequences. The area of Sitia follows. Southern Crete seems to be less vulnerable to such risks.

KEYWORDS: Environmental Hazards, Oil spill incidents, Aegean Sea, Crete.

\section{INTRODUCTION}

Human activities are always linked to benefits and hazards. In the recent years the international community has become increasingly aware of the risks due to major accidents occurring near populated and environmentally sensitive areas. There is also a growing need to ensure that health, environmental and safety issues are addressed as an integral part of social and financial development. This new awareness means a novel approach to prevent or bound the impacts of a natural or technological disaster (flood, forest fire, oil spill, explosion in an oil refinery etc). This can be achieved through an integrated approach to environmental risk assessment (Fedra and Weigkricht, 1995; Fedra, 1993; Goodchild et al., 1996), and safety management where all elements of risk are identified and assessed and where the priority management actions are formulated in an integrated way (Johnson, 1995; Beroggi and Wallace, 1995).

During the two previous decades much work has been done concerning the risk analysis and detection of various environmental disasters. 
Specifically Weaver et al., (2000) studied two flood events in Fort Collins Colorado in terms of risk assessment, while a brief presentation and review of some methods for regional flood frequency analysis was made by the French Group of Statistical Hydrology (GREHYS, 1996). Since floods are difficult facing problems there are some excellent works in Europe concerning various flood events mainly in Northern Italy (Ferreti et al., 2000; Anselmo et al., 1998; Todini, 1999) and the UK (Rowsell, 1999).

Forest fires, from the other hand, is one of the most catastrophic natural disasters burning thousands of hectares in south Europe, Australia and the United States. Much work was done mainly in Spain and France about this natural disaster. Specifically, Regueira et al., (2000) design risk index maps for Galicia Spain in a serie of works, and Gonzalez et al., (1997) studied Forest fire risk assessment using National Oceanic and Atmospheric Administration Advanced Very High Resolution Radiometry (NOAA-AVHRR) images in the Valencia area, Eastern Spain.

Technological accidents cause significant environmental hazards because they release toxic chemicals in the environment contaminating the atmosphere, water (both inland and sea) and soil. Fedra, (1993) made a novel work concerning the risk assessment and management of a similar disaster using GIS tools.

Up to now very little work, as far as author knows, was done for the detection, study and analysing the Risk from oil spill incidents especially in the Mediterranean. Sofotassios et al., (1997) using GIS-based frameworks try to study oil spill emergency management in the Mediterranean.

In this work, we analyze the risks (both environmental and financial) from an ecological disaster as an oil spill incident, which will be happen in the major Mediterranean island of Crete. Crete is one of the very popular destinations for the tourism industry worldwide while there is much financial activity near its seashores. Significant parts of its seashores are also protected areas by international conventions while the island is between the most frequent routes of every kind of ships and especially tankers.

In the following chapter the data used and the methodology adopted is presented. In chapter 3 a description of the application area, among the analysis of the available meteorological and oil spill data is discussed. In the fourth chapter the risk analysis for the environmental sensitive areas as well as for the financial activities is presented, while in the last chapter the main conclusions are drawn.

\section{DATA AND METHODOLOGY. Data Available}

We use two types of data. Wind velocity and direction data from the main anemological stations in the North (Heraklion and Chania) and South (Ierapetra) Crete. The oil spill incidents directory (1995-1999) from the Port Authorities of the main ports of the island.

\section{Methodology}

In this work a new methodology was introduced to handle risk analysis due to oil spill incidents. It is common sense that, rather than attempting to determine exact probabilities of each disaster, a general relational rating system of high, medium and low can be used to identify the probability of the threat occurring. The planning process should identify and measure the probability of all potential risks and the impact on the ecosystem or human/financial activity if that threat occurred. To do this, each part should be analysed separately. According to the above philosophy and introducing priorities concerning the significance of a particular threat we rated the impacts as follows:

$0=$ No impact in the financial activity of the population or no ecological disaster in the protected areas.

$1=$ Noticeable impact, in the financial activity of the population or in the protected areas/ ecosystems.

$2=$ Damage in the financial activity of the population or in the protected areas/ ecosystems.

$3=$ Major damage in the financial activity of the population or in the protected areas/ ecosystems.

To uniformly apply ratings to each potential threat the following assumptions were made:

Although impact ratings could range between 1 and 3 for any activity given a specific set of circumstances, ratings applied should reflect anticipated, likely or expected impact on each area. Each potential threat should be assumed to be "localized" to the activity being rated. Although 
one potential threat could lead to another potential threat, no domino effect should be assumed. The risk assessment should be performed for each financial activity.

To measure the potential risks, a weighted point rating system was developed. Each level of probability can be assigned points as follows: High risk, points 10, Medium risk, points 5 and Low risk, one point. The points assigned to each risk level are introduced in such a way to separate the three different risk levels, quantify the risks and discriminate the results.

To obtain a weighted risk rating, probability points should be multiplied by the highest impact rating for each activity. For example, if the probability of oil spills is high (10 points) and the impact rating to an activity is " 3 ", then the weighted risk factor is $30(10 \times 3)$. Based on this rating method, threats that pose the greatest risk (e.g., 15 points and above) can be identified. We choose this threshold because it represents the beginning of the upper half of the scale.

The validity of this methodology is not site specific since it combines the three possible risk levels with different possible impacts in an area facing a natural or anthropogenic disaster (oil spill, forest fire, flood, avalanches etc.). The scores assigned are indicative to understand in a quantification of risks. It is worth noted that we can add both more impacts and risk levels in proportion of the application we handle.

\section{APPLICATION IN THE AREA OF CRETE Description of the area}

Crete is one of the majors Mediterranean islands, located in the South Aegean Sea. North of the island is the Cretan sea (part of the Aegean Sea), while in the South is the Libyan Sea. Crete consists of 4 prefectures, specifically from west to the east, prefectures of Chania, Rethymnon, Heraklion and Lasithi. There are 5 significant cities located in the north of Crete and one in the South. The capital Heraklion with about 150000 people, Chania with about 80000, Rethymnon with about 30000 and Ag. Nikolaos and Sitia. The city of Ierapetra is located in the Southeast part of the island, with about 15000 habitants. The last three cities are located in the Prefecture of Lasithi.

Crete has about 600000 habitants, but more than 5 million tourists are visited the island during an entire year. The areas of Cretan and Libyan Seas are characterized by heavy marine traffic throughout the year. Especially, navigation through the Libyan Sea (south of Crete) is a common route for tankers and cargo freighters, carrying crude oil and other goods to Europe, through the Suez Canal. The frequency of vessels crossing that area, especially of those carrying crude oil, is expected to rise significantly in the years to come, due to the planned Baku - Ceyhan oil duct. The frequent navigation of tankers through this area enhances the possibility of marine pollution by oil-based waste from the ships as well as from possible shipwrecks.

Cretan sea is mainly used by ferries carrying passengers and goods to and from Crete, as well as ships navigating from the Bosphoros and the Black Sea to the Mediterranean. Tankers are less frequent in this area, yet their number is expected to increase very much in a few years, when the Burgas - Alexandroupolis oil duct will become operational. Due to the tourist traffic that increases dramatically during the summer season, ferries cover the highest percentage of vessels in area, under the present circumstances. Thus, oil waste based pollution is expected to be the main pollutant; the possibility of a shipwreck is less probable, yet existent. From the above it is evident that the two areas, the Cretan and Libyan Seas, present different qualitative and quantitative characteristics, regarding the type, frequency and the annual distribution of the vessels navigating through them.

\section{Meteorology}

The meteorology of the region indicates that Cretan and Libyan seas are dominated by the same, more or less, synoptic scale atmospheric circulation patterns. However the projection of these synoptic systems to the mesoscale, create slightly different wind regimes due to the orientation of the island of Crete. Cretan Sea is characterized by winds blowing from the Northern sector, throughout the year. The frequency of these winds, as it was estimated by the meteorological data available, sums up to about $60 \%$ on a yearly basis, while during summer the percentage is higher due the dominance of the local system of north winds, called Etesians. Southern winds in the area correspond to less than $10 \%$ of the days. The Libyan sea is generally characterized by the same synoptic systems as the Cretan sea, with the 
exception of the Etesians, that are significantly weaker in this area. Thus, the area is characterized by northern winds for more than $55 \%$ of the days. Southern winds, that potentially could transport pollutants towards the area of the southern coast of Crete, represent less than $15 \%$ of the days. The remaining percentage of winds blowing over Cretan sea is calms.

Therefore, it is obvious that, from a solely meteorological point of view, the area of Cretan Sea presents notably greater risk for an accident to affect the coasts of Crete. Unfortunately there is not available data of the sea currents in the whole South Aegean area.

The northern part of Crete has the largest population and activities concentration, since all the major cities of the island are located in this part (Heraklion, Chania, Sitia, Agios Nikolaos, Rethymno), and it is also the most touristicaly developed part of the island with large touristic facilities and beaches.

On the contrary, the southern coast of Crete has only one town present, Ierapetra, and many, mainly not touristicaly organized, beaches.

From the above it is concluded that the risk assessment from a possible oil-spill should be carried out separately for the Libyan and Cretan seas.

\section{Detected oil spill incidents.}

The data provided to us by the Hellenic Ministry of Merchant Marine covers a 5-year period from 1995 to 1999 and referred to detected oil depositions by the Port Authorities. Prior to the analysis, data were checked for outliers. It should be mentioned that the data available are incomplete, since in very few cases the authorities recorded information about the extent of the detected oilspill. From the analysis of the frequency of occurrence of an oil-deposition at sea detected by the Port Authorities during the past five years, it seems that this is not a frequent phenomenon (assuming that all actual incidents were detected). During this period 29 oil-spill incidents were reported in the area of Northern Crete. These were detected by the Port Authorities of Chania (13), Heraklion (9), Sitia (4), Rethymnon (2) and Agios Nikolaos (1). The pollutant was only oilbased. Information regarding the size of the oilspill was reported in only two cases. One of them, detected by the Port Authority of Heraklion had dimensions of about $3 \mathrm{~km}$ and was detectable by a
NOAA satellite (METEOSAT) the other one was about $600 \mathrm{~m}$ and was detected by the Port Authority of Heraklion too. The annual distribution of the oil-spill incidents, according to the data available from the Ministry of Merchant Marine, is presented in Table 1. Subsequently the data were analyzed in order to obtain the monthly distribution of the incidents. Table 2 illustrates that the months with the highest frequency of incidents were June, July and October, while the majority of the incidents ( 15 or $51.7 \%$ ) occurred during the tourism high-season (June to September).

From Table 1 two peaks of incidents are observed, one in 1995 (9 incidents) and a second in 1999 (12 incidents) the area with the most incidents is that under the jurisdiction of the Chania Port authority. In the same table the monthly risk for Northern Crete is presented.

It must be noted that no oil-spill incidents were detected in the area of the Libyan Sea. This can be explained by the prevailing wind fields of the area, the rather limited area of jurisdiction of Southern Crete port authorities and the long distance of Cretan shore for ship routes in international waters.

According to the incidents reported, the areas located at the Southern Crete, as well as the areas under the jurisdiction of Rethymnon and Agios Nikolaos Port Authorities can be considered as low-risk areas regarding the occurrence of an oilspill. The area of the Sitia Port Authority can be considered as a moderate risk area, while the areas under the jurisdiction of Chania and Heraklion Port Authorities, can be characterized as high-risk areas (Table 2).

The analysis of the wind flow fields over the Cretan Sea and the Libyan Sea areas, on an annual as well as on a seasonal basis, shows that, in general, winds from the northern sector (northwest to northeast) prevail. Over the Cretan Sea, their annual frequency is around $60 \%$ (55\% during summer and $65 \%$ during winter), while over the Libyan Sea the corresponding frequencies are a little lower (annual $55 \%$, summer $60 \%$ and winter $50 \%$ ).

Winds from the southern direction in the area of the Cretan Sea appear for nearly $12 \%$ of the days on an annual basis (8\% during summer and $16 \%$ during winter). Over the Libyan Sea the corresponding percentages are $15 \%$ for the whole year, $10 \%$ for summer and $18 \%$ for winter. For the rest of the days (about 20\%) the wind blows from 
Table 1. Oil spill incidents in the area of Crete (For every one Port Authority). (Source Hellenic Ministry of Merchant Marine.)

\begin{tabular}{|c|c|c|c|c|c|c|}
\hline & \multicolumn{7}{|c|}{ Port Authority } \\
\hline Year & Chania & Heraklion & Sitia & Rethymnon & Ag. Nikolaos & Total \\
\hline $\mathbf{1 9 9 5}$ & 6 & 2 & & & 1 & 9 \\
\hline $\mathbf{1 9 9 6}$ & & 1 & & & & 1 \\
\hline $\mathbf{1 9 9 7}$ & 2 & 4 & & & & 6 \\
\hline $\mathbf{1 9 9 8}$ & & 1 & & & & 1 \\
\hline $\mathbf{1 9 9 9}$ & 5 & 1 & 4 & 2 & & 12 \\
\hline Total & 13 & 9 & 4 & 2 & 1 & 29 \\
\hline
\end{tabular}

Table 2. Monthly distribution of oil spill incidents in the area of Crete (For every one Port Authority). Source Greek Ministry of Commercial Marine.

\begin{tabular}{|c|c|c|c|c|c|c|c|c|}
\hline Month & $\begin{array}{l}\text { P.A. of } \\
\text { Chania }\end{array}$ & $\begin{array}{c}\text { P.A. } \\
\text { of } \\
\text { Heraklion }\end{array}$ & $\begin{array}{c}\text { P.A. } \\
\text { of } \\
\text { Sitia }\end{array}$ & $\begin{array}{c}\text { P.A. } \\
\text { of } \\
\text { Rethymnon }\end{array}$ & $\begin{array}{c}\text { P.A. } \\
\text { of Agios } \\
\text { Nikolaos }\end{array}$ & $\begin{array}{l}\text { South } \\
\text { Crete }\end{array}$ & Total & $\begin{array}{c}\text { Level of } \\
\text { Risk } \\
\text { (Temporal) }\end{array}$ \\
\hline January & & 1 & & & & & 1 & Low \\
\hline February & & 2 & & & & & 2 & Moderate \\
\hline March & & & & & & & & Low \\
\hline April & 3 & & & & & & 3 & Moderate \\
\hline May & & & & & & & & Low \\
\hline June & 2 & 2 & & & 1 & & 5 & High \\
\hline July & 3 & 3 & & & & & 6 & High \\
\hline August & & 1 & & & & & 1 & Low \\
\hline September & 1 & & & 2 & & & 3 & Moderate \\
\hline October & 2 & & 4 & & & & 6 & High \\
\hline November & 2 & & & & & & 2 & Moderate \\
\hline December & & & & & & & & Low \\
\hline Annual & 13 & 9 & 4 & 2 & 1 & & 29 & \\
\hline Spatial Risk & High & High & Moderate & Low & Low & Low & & \\
\hline $\begin{array}{c}\text { Fighting of } \\
\text { an oil spill } \\
\text { incident }\end{array}$ & High & Low & Moderate & Moderate & Moderate & High & & \\
\hline
\end{tabular}

western or eastern directions.

The Fighting Authorities for oil-spill marine pollution are based in Heraklion. Accordingly, if an incident occurs in the area of the Heraklion Port Authority the risk is low (e.g. score 1), if the incident occurs in the areas of Rethymnon and Agios Nikolaos (e.g. score 2) and Sitia (e.g. score 3) the risk is moderate, while the risk is high for incidents occurring at Chania (e.g. score 4) or the Southern Crete (e.g. score 5) (Table 2). The points assigned to each risk level are introduced in such a way to separate the different risk levels, quantify the risks and discriminate the results.

\section{RISK ANALYSIS}

Risk analysis for every environmentally sensitive activity or infrastructure

The infrastructure, in the region of Crete that is vulnerable to oil-spills can be classified as follows:

- Protected areas (SPA and NATURA 2000) and locations of special natural beauty

- Zones of Fishing and Pisciculture

- Tourist zones - Tourist Installations and beaches 


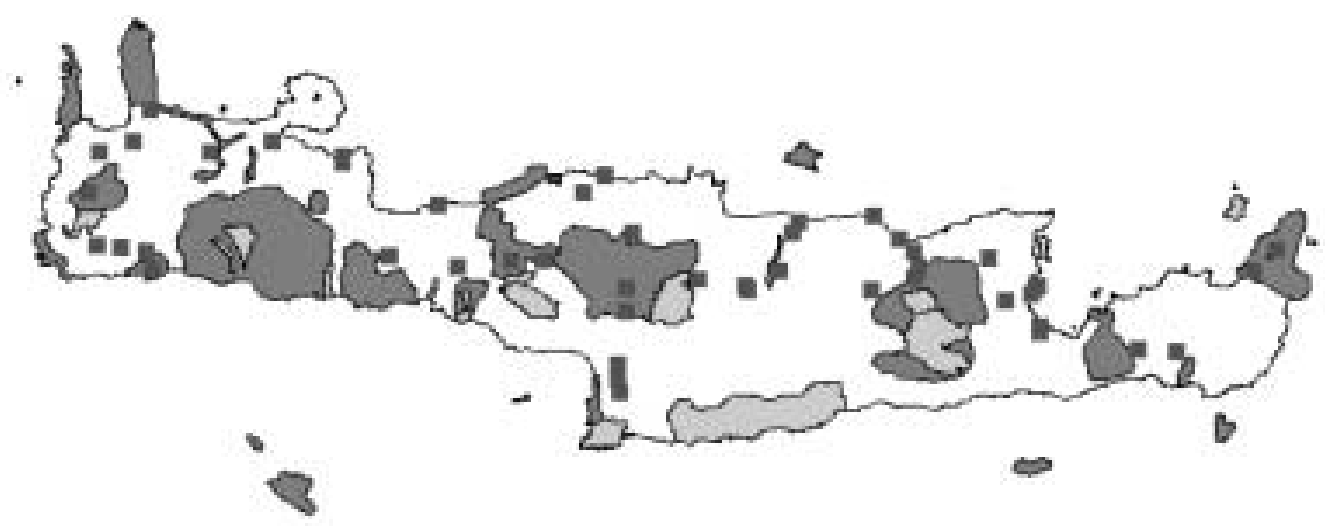

Figure 1. Map of Crete presenting the protected areas NATURA 2000 (Dark Gray) and SPA (Light Gray) as well as the sites of special natural beauty (Squares)

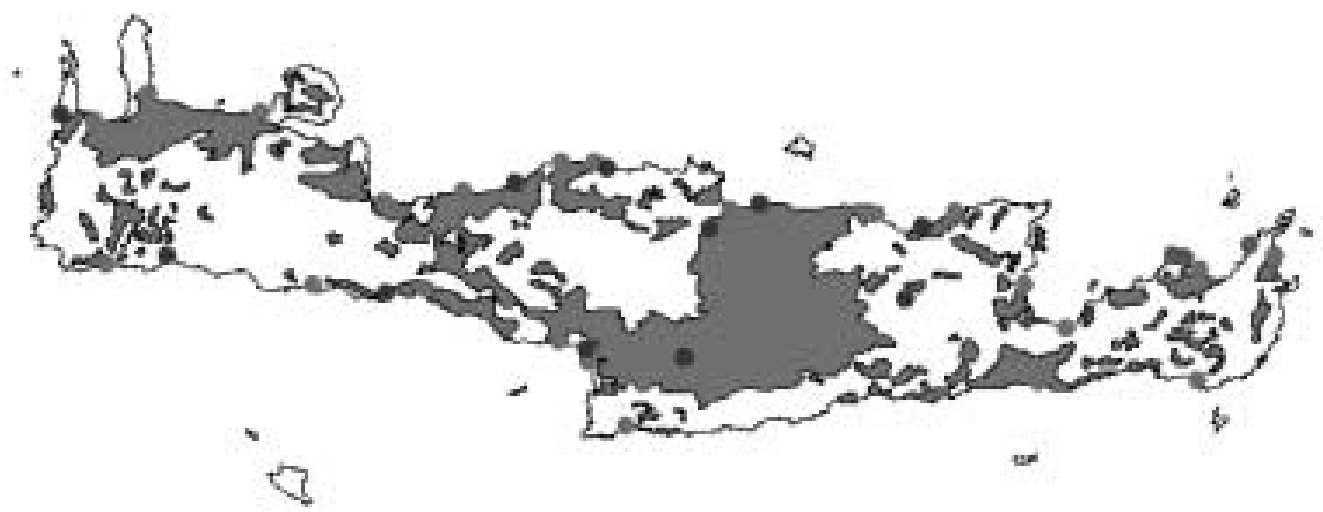

Figure 2. Map of Crete presenting agricultural land (Light Gray) and the most important harbors (Circles)

\section{Protected areas (SPA and NATURA 2000) and locations of special natural beauty}

Figure 1 presents, with different gray scales, the zones designated as SPA and NATURA 2000 in the region of Crete, as well as those characterized as locations of special natural beauty.

These areas are distributed along the coast and rated as follows:

A) Prefecture of Chania, North coast points 3, South coast point 1

B) Prefecture of Rethymnon, North coast points 2

C) Prefecture of Heraklion, North coast points 3

D) Prefecture of Lasithi, North coast points 3

SPA zones are mainly located at the southern coast of Crete, in the Prefecture of Heraklion, and very few in the Prefecture of Chania, and Dionysades Islands of the Prefecture of Lasithi.
NATURA 2000 zones cover almost half the island's northern coastline, almost all of the south coast of Chania Prefecture, as well as the island of Gavdos. Also, NATURA 2000 zones can be found in a small part of the south coasts of the Prefectures of Rethimnon and Heraklion, minute parts of the northern coast of the Lasithi Prefecture, and the islands Dia, Gaidouronisi and Koufonisi, the last two in the Libyan Sea. Following the previously presented incident analysis it is evident that the risk is greater for the northern coast of Crete, which, according to the data available, is the only area where oil-based waste is disposed. Therefore, the areas of the Chania Prefecture located at the northern coast (Kissamos and Gramvousa Peninsulas, Souda, and Kalives) present an increased probability to be contaminated by an oil-spill, while according to Table 2 this probability is higher during the May-October period, when the wind blows from the North. 


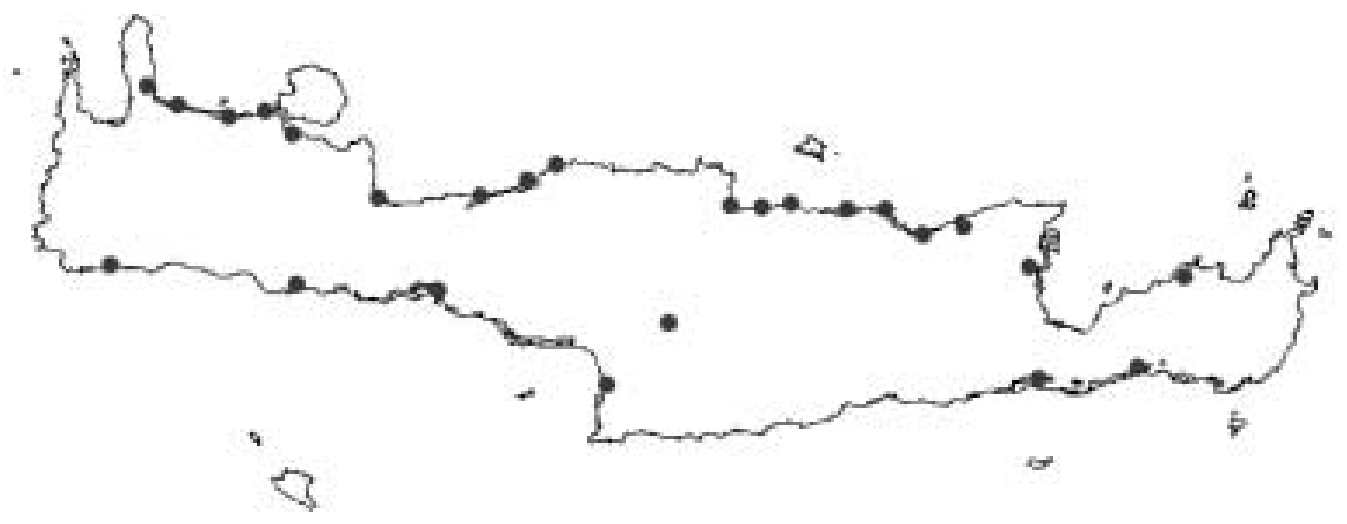

Figure 3. Map of Crete presenting the touristic installations, zones and beaches

Areas along the northern coast of Rethymnon Prefecture, protected under the NATURA 2000, as well as the locations of special natural beauty, have a very low degree of risk that is greater during the warm period of the year. In the Prefecture of Heraklion, the locations of special natural beauty along the northern coast and the island of Dia present high risks, according to Table 2, that increases during the summer period when the wind blows from the North. The zones of special natural beauty located at Agios Nikolaos Bay, in the Lasithi Prefecture, present low risk that is a little higher during the summer and when the wind blows from northern directions. In this Prefecture, the eastern peninsula and Dionysades islands present moderate risk that increases during summer under northern winds. Finaly, regarding the southern coast the degree of risk is low, increasing in the event of southern winds.

Despite the fact that fishing is intense both at the North and at the South coasts of Crete, there were no data available regarding the fishing zones most frequently used. So, considering the whole area as a potential fishing zone in a distance of 20 $\mathrm{Km}$ from the coast, the risk is greater for the marine areas of the Prefectures of Heraklion and Chania (northern coasts), moderate for the areas of the Prefecture of Rethymnon (northern coast), and Agios Nikolaos and Sitia of the Prefecture of Lasithi. The southern coasts of Crete present low risks that increase when the wind blows from the south. Regarding the pisciculture areas, according to the data available, they are located at the area of Sitia, therefore presenting moderate risk increasing during the summer period when the wind blows from the north.

\section{Touristic zones - Touristic Installations and Beaches}

Figure 3 presents the tourism zones, and the beaches along with important hotel installations. As can be seen from this figure the existing infrastructure is mainly concentrated at the northern coast of Crete.

The region with the heaviest touristic infrastructure, according to the data available, seems to be that of Chania, especially between the peninsulas of Kissamos and Souda, as well as the bay of Souda. These areas, following the preceding analysis, present high risks, increasing during the summer period with northern winds. The whole northern coast of the Heraklion Prefecture, and especially the area to the east of Heraklion, is characterized by dense touristic infrastructure (beaches - hotels) and according to the analysis presented above, presents a high degree of risk that increases during the summer period with northern winds. The area of the Prefecture of Rethymno also has significant infrastructure, especially nearby the city of Rethymno. The area presents low risk than, nevertheless, increases during the summer period with northern winds. The area of Agios Nikolaos, at the Lasithi Prefecture, is the one with the better touristic infrastructure, and according to the analysis so far, presents low risk that increases during the summer period with northern winds. In the area of Sitia there are less hotel units but the degree of risk is higher especially during summer with northern winds.

At the South Crete, in the Lasithi Prefecture, where the whole area of Ierapetra is organized for tourism, the risk is low and increases during summer with southern winds. 
Finally, at the south coast of Rethymnon where the touristic infrastructure is also significant the risk is low and increases during summer with southern winds.

\section{Combined Risk Analysis}

Based on the analysis above and the data available it was decided to combine the partial risks identified for the various areas of Crete. Towards this, a risk-scoring scheme was introduced in this work. The following scheme was devised for the areas of jurisdiction of the four Port Authorities of the Northern Crete and the Southern Crete as a whole. Accordingly, using Table 2 and the monthly frequency of oil-spill occurrence, each month of high risk was assigned a high score (e.g. 10), moderate risk months scored with a moderate one (e.g. 5) and low risk months scored with a low risk score (e.g. 1). From this Table, based on the number of incidents, the areas of Chania and Heraklion present high risk, Sitia presents moderate risk and Ag. Nikolaos, Rethymno and South Crete present low risk. It must be noted that this rating is indicative and could be used in any area facing natural or anthropogenic disasters.

It is significant to examine the behavior of the wind flow regimes that could push an oil-spill towards the coast. If the winds are blowing from the northern sector the oil spills in the Cretan Sea could affect the coasts of it. Besides to Northern Crete a similar problem could eventuate for the Southern Crete only with winds blowing from the south sector. So, for the region of Northern Crete, if the percentage of days with northern winds (favorable) was more than $50 \%$ then it scored as high risk (e.g. 3 points), if the percentage was between 20 and $50 \%$ it scored as moderate risk (e.g. points 2) and if it was below $20 \%$ it scored as low risk (e.g. point 1). For the region of Southern Crete, if the percentage of days with southern winds (favorable) was more than 50\% then it scored accordingly as high risk (points 3 ), if the percentage was between 20 and $50 \%$ it scored as moderate one (points 2) and if it was below $20 \%$ it scored as low risk (point 1 ).

Another score was assigned relative to the disaster (financial or environmental) that could be caused by an oil spill. In case that the oil spill affected a fishing-pisciculture are then it scored 3, if a touristic installation - beach was affected the incident scored 2, while if the affected zone was a protected ecosystem or zone, the incident scored 1. This scoring system was based on the relative economic strength of the affected activity.

Finally, depending on the distance between the incident and the location of the oil spill Fighting Authority, the Prefecture of Heraklion scored 1, Rethymno and Lasithi scored 2, the Prefecture of Chania scored 3 and Southern Crete scored 4. The scores introduced here, were not chosen arbitrarily. The points assigned to each risk level are introduced in such a way to separate the different risk levels for the various activities of the citizens and threats to the environment, quantify the risks, discriminate the results and follow sensible arguments.

Following to the above, the combined Risk Units for each month and area were calculated according to the following formula:

$$
R U_{i j}=\alpha_{i} \times b_{j} \times\left(c_{k}+d_{m}+e_{n}\right)
$$

\section{RU Risk Units}

i month $\mathrm{i}=1, \ldots, 12$

$\mathrm{j}$ area (Heraklion,Chania,Sitia, Agios Nikolaos, Rethymnon, South Crete) $j=1, \ldots, 5$

$\mathrm{a}_{\mathrm{i}}$ month factor, $\mathrm{a}_{\mathrm{i}}=1,5,10$

$b_{j}$ area factor, $b_{j}=1,2,3$

$\mathrm{c}_{\mathrm{k}}$ prevailing wind flow (Northern, Southern) $\mathrm{c}_{\mathrm{k}}$ $=1,2, \mathrm{k}=1,2$

$\mathrm{d}_{\mathrm{m}}$ Kind of disaster (fishing area, tourist installation, protected area), $\mathrm{d}_{\mathrm{m}}=1,2,3, \mathrm{~m}=1,2,3$

$e_{n}$ possibility of early fighting, $e_{n}=1,2,3,4,5$, $\mathrm{n}=1, \ldots, 5$

When the combined Risk Units (RU) are less than 80 , then the risk is considered to be low, when RU is between 80 and 150 the risk is moderate and for more than 150 risk units the risk is high. We choose this threshold, for the high risk, because it represents the beginning of the upper half of the scale.

The application of the above formula produced the results presented in Figure $4 \mathrm{a}$.

The validity of the rating system introduced in this paper was tested by the data of 1999 which was initially excluded from the calculations and shows that more than $80 \%$ of the cases was in good agreement with the results.

From Figure 4a it can be seen that low risk months for fishing and touristic zones January, March, May, August and December, while for the protected areas low risk months are January, February, March, April, May, July, August, 

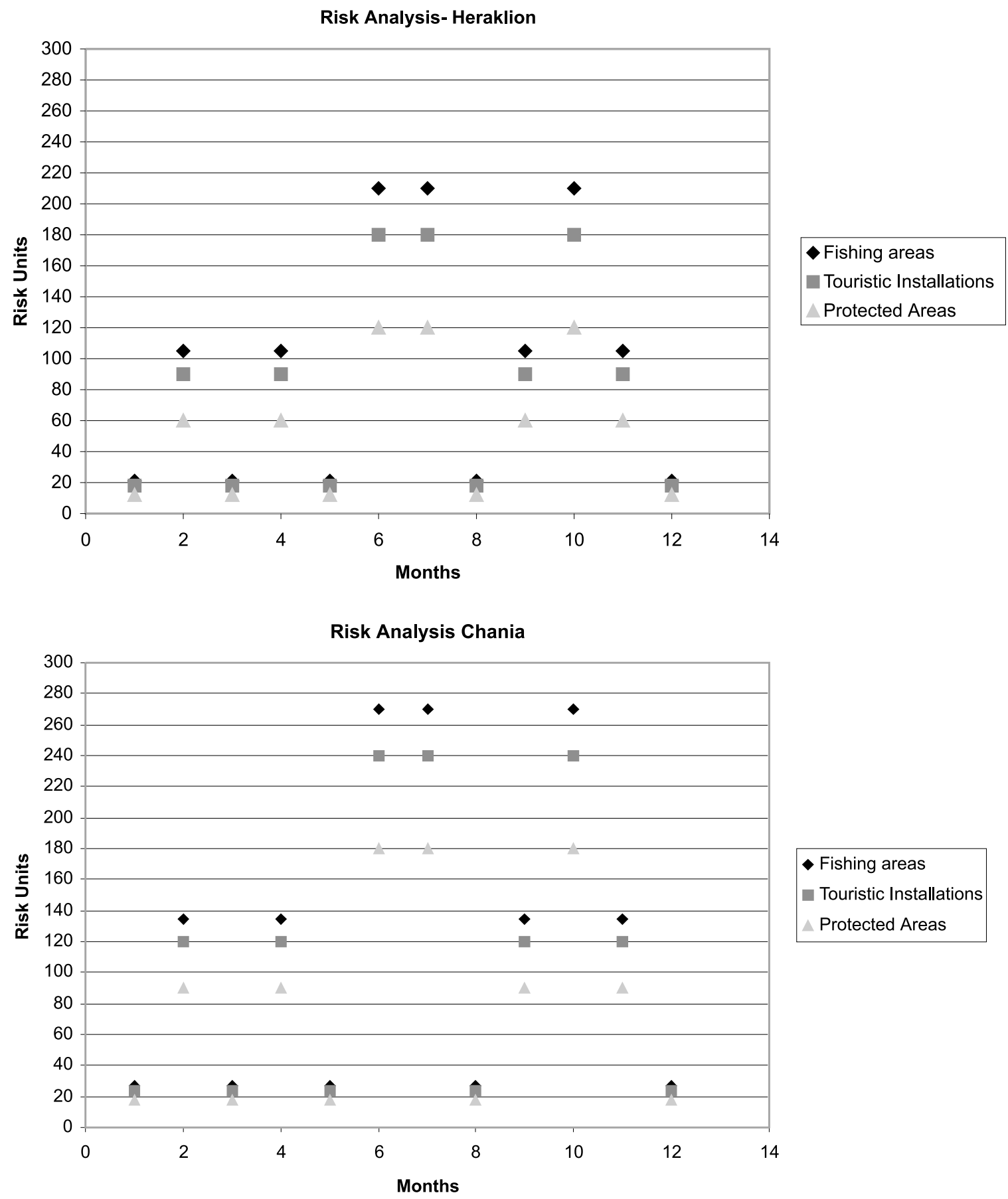

Figure 4a,b. Risk Analysis for Fishing areas, Touristic Installations and Protected Areas in (a) Heraklion, (b) Chania. Numbers are in risk units

November and December. Moderate risk months for fishing and touristic zones are February, April, September and November, while for the protected areas the respective months are June, July and October. High risk months for both fishing and touristic zones are June, July and October.
Figure $4 b$, for Chania, indicates low risk for fishing, touristic, and protected zones during January, March, May, August and December. The risk is moderate during February, April, September and November and high during June, July and October, for all zones alike. 


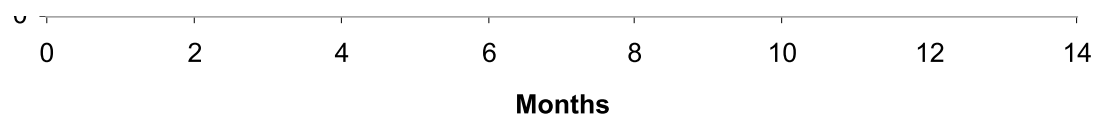

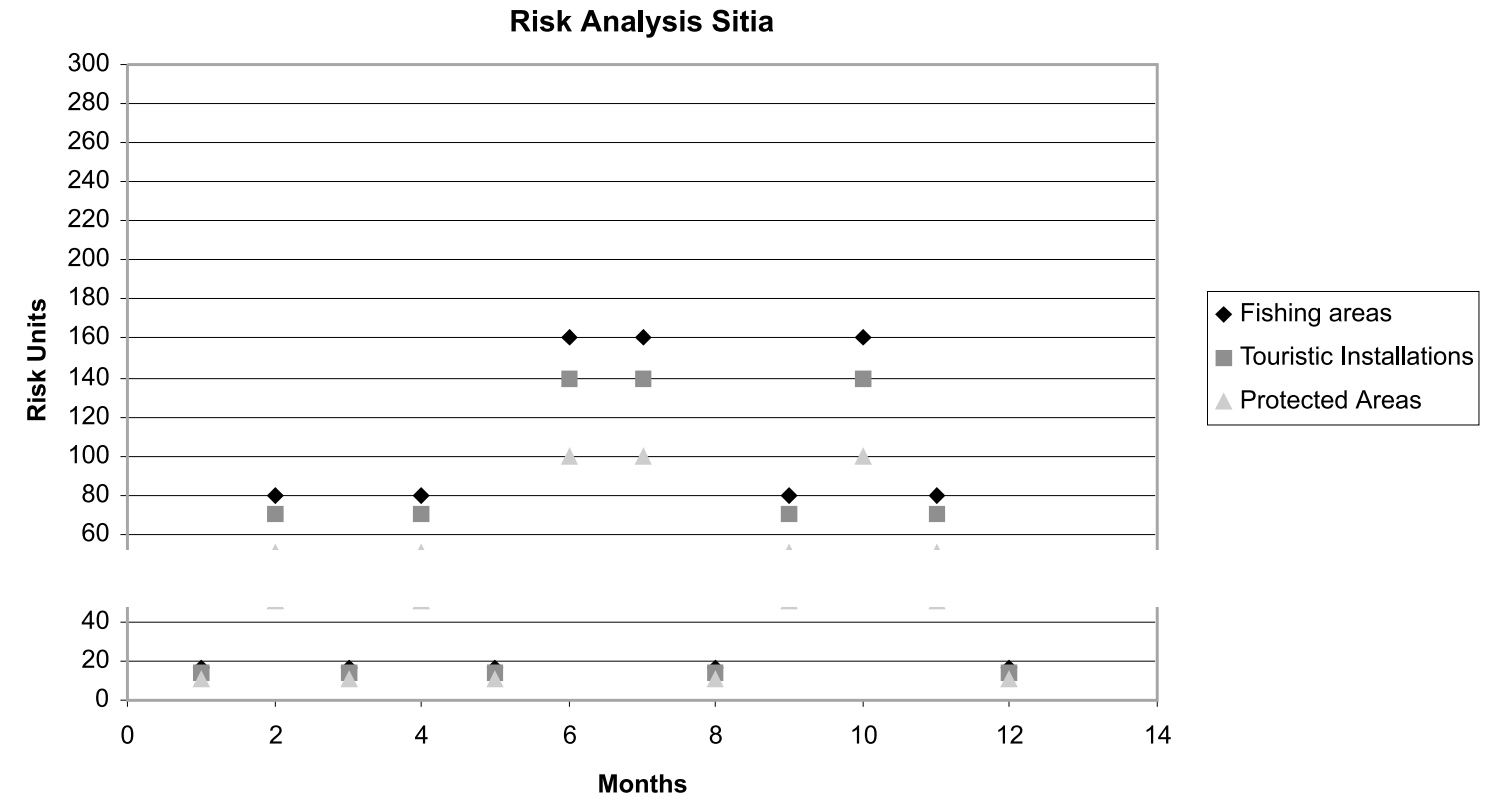

Risk Analysis Rethymon-Ag Nikolaos

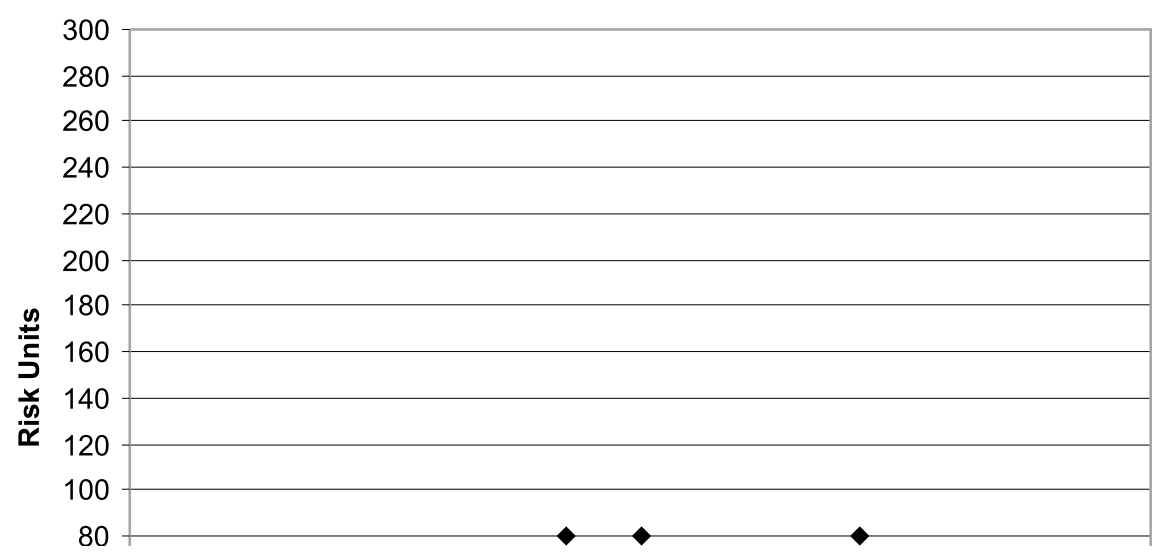

Fishing areas

Touristic Installations

Protected Areas

Figure 4c,d. Risk Analysis for Fishing areas, Touristic Installations and Protected Areas in (c) Sitia, (d) Rethymnon and Agios Nikolaos. Numbers are in risk units

Figure 4c, for Sitia, presents low risk for fishing zones during January, March, May, August and December while for touristic and protected zones the low risk months are January, February, March, April, May, August, September, November and December. The moderate risk months are February, April, September and November for the fishing zones, and June, July and October for the touristic and the protected zones. High risk for fishing zones is estimated for June, July and October.

Combined risks for Rethymno and Agios Nikolaos are presented in Figure 4d. Low risks were estimated for touristic and protected zones throughout the year, while for the fishing zones low risk is for January, February, March, April, May, August, September, November and December. 
Fishing Areas

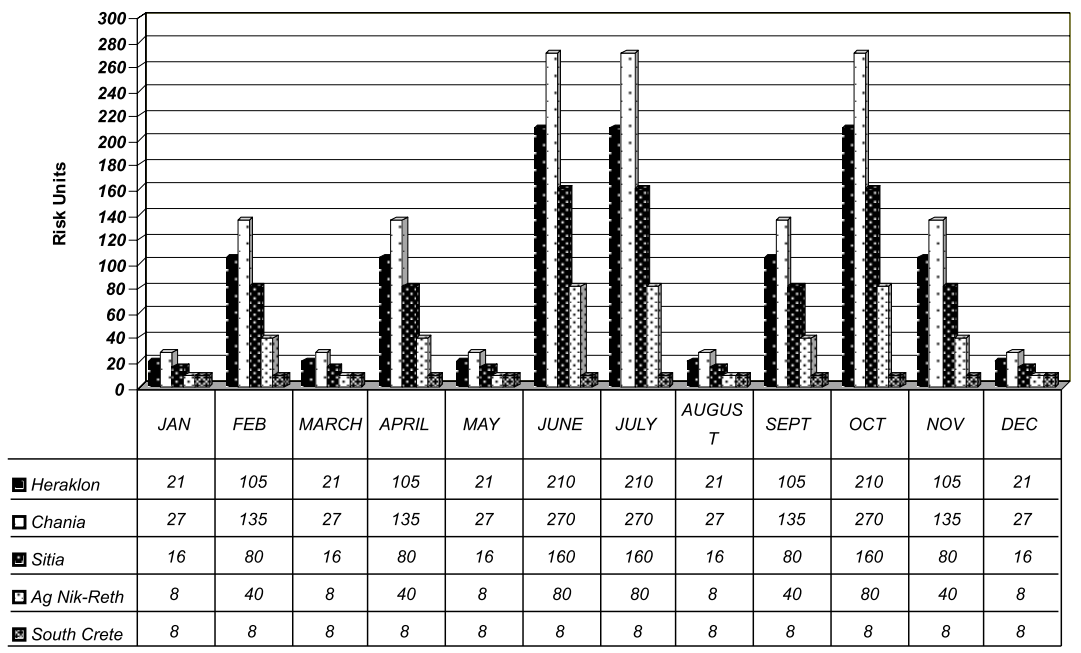

Figure 5. Risk Combination for Fishing areas and pisciculture installations in Crete. Numbers are in risk units

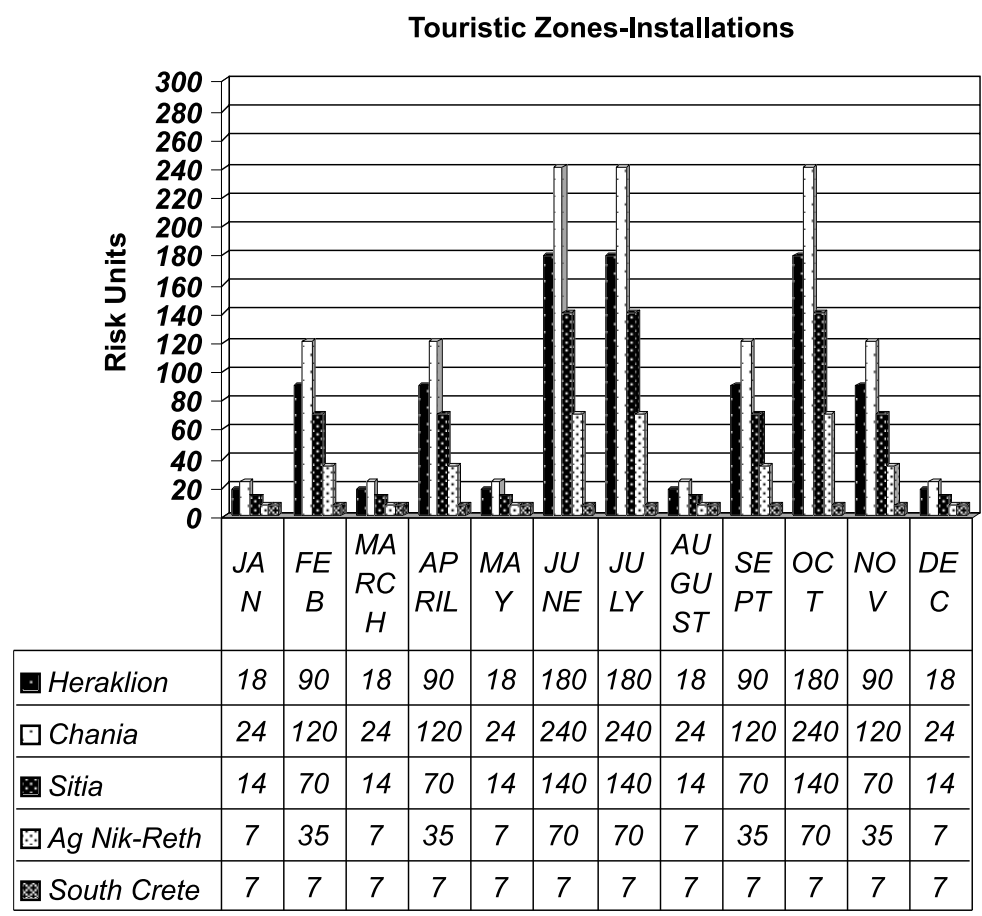

Figure 6. Risk Combination for Tourist zones, and Touristic installations in Crete. Numbers are in risk units

Moderate risk is associated with June, July and October but only for the fishing zones, while there is no instance of high risk for any month or zone. Finally, for Southern Crete only low risks were estimated for all months and for fishing, touristic and protected zones alike.

The final step was to combine the various areas per activity. Thus, for fishing-pisciculture the areas of Chania, Heraklion and Sitia present high risk during
June, July and October. The risk is moderate for the areas of Chania and Heraklion during February, April, September and November (Figure 5).

For the touristic zones, beaches, hotel units the risk is high for Chania and Heraklion during June, July and October, while the risk is moderate for Sitia during June and July and for Chania, Heraklion during February, April, September, and November (Figure 6). 


\section{Protected Areas}

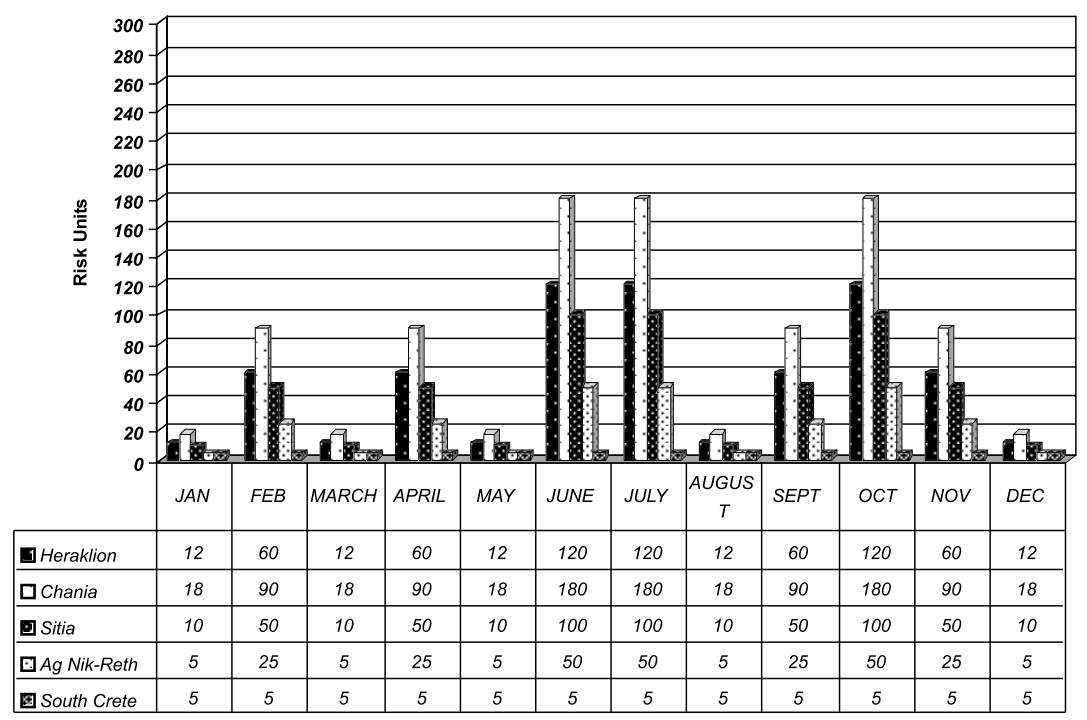

Figure 7. Risk Combination for Protected areas (SPA and NATURA 2000) and sites of special natural beauty. Numbers are in risk units

The protected areas and the location of special natural beauty are at a high risk during June, July and October, when located at Chania, and at moderate risk when they are located at Heraklion or Sitia. Chania present moderate risk during February, April, September and November (Figure 7).

\section{CONCLUSIONS}

From the analysis presented above the following conclusions could be drawn concerning the impact of a possible oil spill incident:

- The region of Chania, especially between the peninsulas of Kissamos and Souda, as well as the bay of Souda, present high risks, increasing during the summer period with northern winds.

- The whole northern coast of the Heraklion Prefecture, and especially the area to the east of Heraklion, presents a high degree of risk that increases during the summer period with northern winds.

- The area of the Prefecture of Rethymno (Agios Nikolaos and Sitia in the North and Ierapetra in the South) presents low risk than, nevertheless, increases during the summer period with northern winds.

- The areas of Southern Crete presented low risk which increases during periods with domination of Southern winds.

\section{ACKNOWLEDGMENTS}

This work is partly funded by the European Union, DGXI, PROMED project, ENV/GR/592. We would like also to thank the Hellenic Ministry of Merchant Marine, the Greek National Meteorological Service and the Region of Crete that kindly offered information related to past oil spill incidents and other data used in this work.

\section{REFERENCES}

Anselmo V., Galeati G., Palmieri S., Rossi U. and Todini E. (1998), Flood risk assessment using an integrated hydrological and hydraulic modelling approach: a case study, Journal of Hydrology, 175, 533-554.

Beroggi G.E.G. and Wallace W.A. (1995), Computer Supported Risk Management, Kluwer Academic Publishers, Dordrecht, The Netherlands, pp. 372.

Fedra K. and Weigkricht E. (1995), Integrated Information Systems for Technological Risk Assessment. In: Computer Supported Risk Management, G.E.G. Beroggi and W.A. Wallace [Eds.] Kluwer Academic Publishers, Dordrecht, The Netherlands, pp. 213-232. 
Fedra K. (1993), GIS and Environmental Modeling In: Environmental Modeling with GIS, M.F. Goodchild, B.O. Parks and L.T. Steyaert [Eds.], Oxford University Press, pp. 35-50.

Ferretti R., Low-Nam S. and Rottunno R. (2000), Numerical simulations of the Piedmont foold of 4-6 November 1994, Tellus, 52, 162-180.

Gonzales A. F., Cuevas J. M., Casanova J.L., Calle A. and Illera P. (1997), Forest fire risk assessment using NOAA AVHR images in the Valencia area, Eastern Spain, International Journal of Remote Sensing, 18, 2201-2207.

Goodchild F.M., Steyaert L.T., Parks B.O., Johnston C., Maidment D., Crane D. and Glendinning S. (1996), Progress and Research Issues, In: GIS and Environmental Modeling, GIS World Books, Fort Collins, CO, pp. 486.

GREHYS (1996), Presentation and review of some methods for regional flood frequency analysis, Journal of Hydrology, 186, 63-84.

Johnson O. (1995), GIS Applications in Emergency Management. In: Computer Supported Risk Management, G.E.G. Beroggi and W.A. Wallace [Eds.], Kluwer Academic Publishers. Dordrecht, The Netherlands, pp. 133-142.

Nunez-Regueira L. J., Rodriguez A. and Proupin-Castineiras J. (2000), Design of risk as a tool to prevent forest fires in the humid Atlantic zone of Galicia (NW Spain), Thermochomica Acta, 349, 11-69.

Rowsell P. (1999), Flood hazard assessment, modelling and management: Results from the EUROflood project, Environments, 27, 79-95.

Sofotassios D., Tzimas G. and Tsakalidis A. (1997), A GIS-based Framework for oil-spill emergency management in the Mediterranean Sea. In: Proceedings of the JEC-GI '97, Hodgson S., Rumor M. and Harts J.J. [eds.], From Research to Application through Cooperation, April 16-18, Vienna, IOS Press, Amsterdam, 1, 412-422.

Todini E. (1999), An operational decision support system for flood risk mapping, forecasting and management, Urban Water, 1, 131-143.

Weaver J., Gruntfest E. and Levy G. (2000), Two floods in Fort Collins Colorado:Learning from a natural disaster, Bulletin of the American Society, 18, 2359-2365. 